\title{
A Holistic Approach to Understanding the Desorption of Phosphorus in Soils
}

Daniel Menezes-Blackburn, ${ }^{* \dagger}{ }^{\dagger}$ Hao Zhang, ${ }^{* \dagger}$, Marc Stutter, ${ }^{\ddagger}$ Courtney D. Giles, ${ }^{\ddagger}$ Tegan Darch, ${ }^{\S}$ Timothy S. George, ${ }^{\neq}$Charles Shand, David Lumsdon, ${ }^{\star}$ Martin Blackwell, ${ }^{\S}$ Catherine Wearing, ${ }^{\dagger}$ Patricia Cooper, ${ }^{+}$Renate Wendler, Lawrie Brown, ${ }^{\ddagger}$ and Philip M. Haygarth ${ }^{\dagger}$

${ }^{\dagger}$ Lancaster Environment Centre, Lancaster University, Lancaster, LA1 4YQ, U.K.

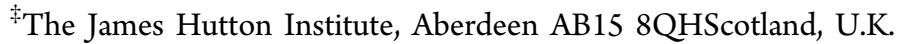

${ }^{\S}$ Rothamsted Research, North Wyke, Okehampton, Devon EX20 2SB, U.K.

\author{
Supporting Information
}

ABSTRACT: The mobility and resupply of inorganic phosphorus (P) from the solid phase were studied in 32 soils from the UK. The combined use of diffusive gradients in thin films (DGT), diffusive equilibration in thin films (DET) and the "DGT-induced fluxes in sediments" model (DIFS) were adapted to explore the basic principles of solid-to-solution $\mathrm{P}$ desorption kinetics in previously unattainable detail. On average across soil types, the response time $\left(T_{\mathrm{c}}\right)$ was $3.6 \mathrm{~h}$, the desorption rate constant $\left(\mathrm{k}_{-1}\right)$ was $0.0046 \mathrm{~h}^{-1}$, and the desorption rate was $4.71 \mathrm{nmol}^{-1} \mathrm{~s}^{-1}$. While the relative DGTinduced inorganic $\mathrm{P}$ flux responses in the first hour is mainly a function of soil water retention and $\% \mathrm{C}_{\text {org }}$ at longer times it is a function of the $\mathrm{P}$ resupply from the soil solid phase. Desorp-

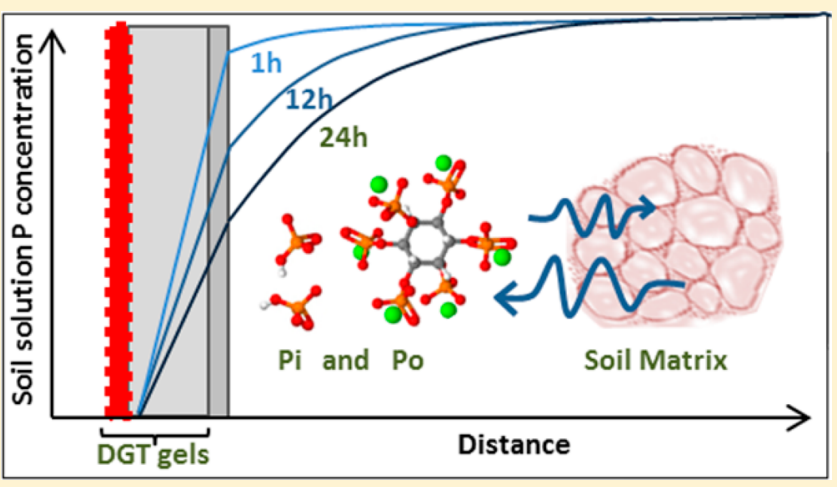
tion rates and resupply from solid phase were fundamentally influenced by $\mathrm{P}$ status as reflected by their high correlation with $\mathrm{P}$ concentration in FeO strips, Olsen, $\mathrm{NaOH}-\mathrm{EDTA}$ and water extracts. Soil $\mathrm{pH}$ and particle size distribution showed no significant correlation with the evaluated mobility and resupply parameters. The DGT and DET techniques, along with the DIFS model, were considered accurate and practical tools for studying parameters related to soil $\mathrm{P}$ desorption kinetics.

\section{INTRODUCTION}

Modern agriculture is dependent on phosphorus (P) fertilizer applications to maintain their productivity. The application of $\mathrm{P}$ fertilizer in soil is an inefficient practice since, in general, just a small fraction of the applied $\mathrm{P}$ is taken up by plants and represents an inadequate use of finite mineral resources. ${ }^{1}$ Phosphorus is perhaps, among all the essential plants macronutrients, the one with most limited bioavailability in soils. ${ }^{2}$ To ensure optimal plant growth, $\mathrm{P}$ fertilizers are applied to agricultural soils in excess of plant requirements to overcome soil $\mathrm{P}$ fixation processes and maintain soil solution $\mathrm{P}$ at sufficient levels for plant growth. ${ }^{3}$ The use of $\mathrm{P}$ in excess of crop requirements and the inefficient acquisition of soil $\mathrm{P}$ by plants have led to an accumulation of a largely unavailable pool of soil $\mathrm{P}$ as well as the eutrophication of receiving water courses.

Phosphorus from freshly added $\mathrm{P}$ fertilizer adsorbs to soil particles, displacing other anions with lower affinity to the surface of the soil solid phase. ${ }^{3}$ Precipitation with metals and their oxy/ hydroxides also plays an important role in the short term (hours to days) fixation of soil P. ${ }^{4}$ The reduced mobility of $\mathrm{P}$ in soils is one of the main factors that influences its limited availability. ${ }^{5}$ Differences in soil mobility and P fixing capacity are generally assumed to be a function of soil type and the associated surface properties of their minerals. Phosphorus mobility in soils has been commonly studied by quantifying $\mathrm{P}$ in different extracts as a way of assessing its lability (availability). Lability is defined as the likelihood of $\mathrm{P}$ undergoing a change of state; in this study it is generally referred to as the process of $\mathrm{P}$ desorption from the surface of soil particles induced by the depletion of solution concentration (e.g., due to the $\mathrm{P}$ uptake by plants). The $\mathrm{P}$ desorbed to soil solution is therefore assumed to be readily plantavailable. In this study we explore the use of diffusive gradient in thin films (DGT) and diffusive equilibrium in thin films (DET) as tools to assess intrinsic $\mathrm{P}$ mobility properties of different agricultural soils. The similarities of this system to a plant root and its usefulness as "plant proxy" to study bioavailability was reviewed by Degryse et al. (2009). ${ }^{6}$ Better knowledge of these mobility properties will allow better understanding and management of the administration of appropriate amounts of $\mathrm{P}$ for

Received: November 2, 2015

Revised: February 22, 2016

Accepted: February 24, 2016

Published: February 25, 2016 
agricultural production, while minimizing environmental losses and optimizing $\mathrm{P}$ inputs.

It is well established that plant $\mathrm{P}$ uptake is limited by its diffusion and resupply from solid phase in soils. ${ }^{5}$ The combined use of DGT and DIFS offer a unique opportunity to assess the basic principles of $\mathrm{P}$ movement through soil in previously unattainable detail. ${ }^{7,8}$ Although the sorption/desorption of $\mathrm{P}$ has been studied on many model clays and soils, there is still limited knowledge of the $\mathrm{P}$ geochemical response to perturbations in natural conditions (e.g., mineral and organic fertilizer application, tillage systems, crop type, irrigation, etc.), including how soil properties may drive the variations in its response to these perturbations.

The specific aims of this study were (a) to evaluate the use of DGT and DET techniques, and the DIFS model, as tools to estimate the variability of $\mathrm{P}$ distribution coefficients, (de)sorption rate constants, depletion distance, and other parameters reflecting $\mathrm{P}$ resupply from soil solid phase across a range of $32 \mathrm{UK}$ soils; and (b) to contrast the data obtained by DGT, DET, and DIFS to standard soil $\mathrm{P}$ tests, physical properties, $\%$ organic $\mathrm{C}$, oxalate extractable $\mathrm{Fe}, \mathrm{Al}$, and $\mathrm{pH}$ in order to evaluate their relative contribution to $\mathrm{P}$ mobility in agricultural soils. More broadly, the work aimed to develop and apply this new approach of resolving and understanding soil phosphorus exchange and release kinetics.

Theory. The DGT device contains a binding layer ( $\mathrm{P}$ sink) and a diffusive layer that modulates the diffusion of $\mathrm{P}$ from soil solution. The time-averaged $\mathrm{P}$ concentration $\left(\mathrm{P}_{\mathrm{DGT}}\right)$ in the soil solution at the outer surface of the DGT device is calculated from the P mass accumulated on the DGT biding layer using Ficks law of diffusion. The theory behind the calculation of DGT parameters can be found in Zhang et al. (1995). ${ }^{15}$ Using $P_{\mathrm{DGT}}$, a soil effective concentration $\left(\mathrm{P}_{\mathrm{E}}\right)$ can be calculated, accounting for both the solution concentration and the adsorbed concentration that can be mobilized by depleting soil solution $P$. The $P_{E}$ is calculated from $\mathrm{P}_{\mathrm{DGT}}$ using the $R_{\text {diff }}$ ratio, which is estimated using a numerical model of the DGT-soil system (DIFS model) by setting input parameters emulating diffusion supply only. The theory behind the $\mathrm{P}_{\mathrm{E}}$ calculation has been previously discussed by Zhang et al. (2001; 2004) ${ }^{9,10}$ In this study we are also interested in solving the DIFS model using empirically measured input parameters in order to estimate the variability of response time of the system, (de)sorption rate constants, $\mathrm{P}$ depletion distance and other parameters reflecting $\mathrm{P}$ resupply from solid to solution phase across a range of different soils.

\section{MATERIAL AND METHODS}

Soil Samples and Characterization. Samples used in this study were collected from 32 representative UK soils and characterized by Stutter et al. (2015). ${ }^{11}$ These had been previously collected across UK sites comprising mostly arable, grassland and several moorland topsoils in a study of soil $\mathrm{P}$ speciation and cycling according to soil organic C, land use and assumed $\mathrm{P}$ fertilizer inputs. As part of this earlier study, characterization included soil $\mathrm{pH}$, oxalate extractable $\mathrm{Al}$ and $\mathrm{Fe}, \mathrm{P}$ saturation index (Psat) soil organic carbon, microbial biomass $P$, total $\mathrm{P}$ and inorganic $\mathrm{P}$ in Olsen, $\mathrm{NaOH}$, citric acid and water extracts. This detailed characterization was used here to draw interrelations between DGT-based parameters and the physicochemical background properties studied by Stutter et al. (2015). ${ }^{11}$ Please refer to the original paper for the methodological details of the mentioned parameters.
Gel Preparation and Assembly of DGT and DET Devices. DGT cylindrical devices designed for soil deployment (DGT Research Ltd., Lancaster-UK) consisted of a binding and a diffusive gel layer tightly packed into a plastic support comprised of a backing plate and a front plate with an exposure window $(A=$ $\left.2.54 \mathrm{~cm}^{2}\right)$. Diffusive gels $(0.78 \mathrm{~mm})$ were placed on top of a binding layer (gel containing ferrihydrite) and a $0.13 \mathrm{~mm}$ thick poly(ether sulfone) filter $(0.45 \mu \mathrm{m})$ was placed on top of the diffusive gel for physical protection. The filter layer has been shown to behave as an extension of the diffusive layer. ${ }^{12}$ The DET devices contained only the diffusive gel $(0.78 \mathrm{~mm})$ and the membrane filter tightly packed into a plastic support with similar dimensions to the ones used for the DGTs.

The diffusive gels containing acrylamide cross-linker (DGT Research Ltd., Lancaster-UK) were prepared and cast according to published procedures. ${ }^{12}$ To prepare the ferrihydrite gel for the binding layer, diffusive gels $(0.78 \mathrm{~mm})$ were incubated for $2 \mathrm{~h}$ in a $0.1 \mathrm{mM} \mathrm{FeCl}_{3}$ aqueous solution to allow uniform distribution of Fe inside and outside of the gels. ${ }^{13}$ Each gel was then placed in a freshly prepared $0.05 \mathrm{M}$ 2-(N-Morpholino)ethanesulfonic acid (MES) $\mathrm{pH} 6.7$ buffer for $30 \mathrm{~min}$ to allow the ferrihydrite to precipitate. The gels were then washed 3 times every $2 \mathrm{~h}$ with reagent grade water and stored at $4{ }^{\circ} \mathrm{C}$ in $0.01 \mathrm{M} \mathrm{NaNO}_{3}$ solution.

DGT Deployment. Soil samples (150 g air-dried) were adjusted to approximately 50\% water holding capacity (WHC) with ultrapure water $(18.2 \mathrm{M} \Omega \mathrm{cm}) 3$ days before DGT and DET deployment. $24 \mathrm{~h}$ before deployment, the soil slurry was prepared by mixing and continuously adding ultrapure water until maximum retention (MR) was reached. A visual assessment of soil malleability and the glistening of water on the soil surface was used to determine MR. This subjective criteria of setting maximum water retention (or near maximum) in the slurry was verified in several pretests. In the cases where too much water was added, liquefying the sample or leaving a film of water on the surface of the slurry, more soil was added to the mixture, and the whole procedure was repeated to those cases using the correct moisture content. These criteria were used for 30 of the 32 used soils; however, they were not suitable for Dartmoor and Tentsmuir soils. Dartmoor is a highly organic (44\% organic C), low density $\left(0.38 \mathrm{~g} \mathrm{~cm}^{-3}\right)$, and very high porosity $(0.87 \mathrm{v} / \mathrm{v})$ leading to high water retention during the slurry preparation. Because soil glistening and plasticity were not obvious criteria for this soil, the optimum slurry retention was determined by pressing the organic matrix to check its saturation. Tentsmuir, on the other hand, is a sandy soil and optimum slurry retention was determined as the maximum moisture before a free film of water could be formed on the surface of the mixture. For each soil, three independent slurry preparations were made, and for each slurry preparation 2 independent DGT and DET deployments were performed.

In all cases, the soil pores are assumed to be filled with water and no air was trapped in the soil slurry, the final moisture concentration was used to determine the particle concentration (ratio between dry weight and soil solution), porosity (\% of volume occupied by water) and tortuosity using the equation proposed by Boudreau (1996). ${ }^{7}$ Physical properties of the samples are displayed in Table 1. DGT devices were deployed after $24 \mathrm{~h}$ by gently pressing them against the soil slurry while ensuring complete surface contact. The air temperature was accurately monitored every hour and averaged for use in further calculation of diffusive coefficients. 
Table 1. Physical Properties from Dry Soils and Slurries Prepared for Diffusive Gradient in Thin Films Analysis ${ }^{a}$

\begin{tabular}{|c|c|c|c|c|c|c|c|c|c|}
\hline \multirow[b]{2}{*}{ soil } & \multirow{2}{*}{$\frac{\mathrm{WHC}}{\mathrm{g} \mathrm{g}^{-1}}$} & \multicolumn{2}{|c|}{ slurry retention } & \multirow{2}{*}{$\frac{P_{c}}{g \mathrm{~cm}^{-3}}$} & \multirow{2}{*}{$\frac{\rho_{\mathrm{s}}}{\mathrm{g} \mathrm{cm}}$} & \multirow{2}{*}{$\frac{\rho_{\mathrm{o}}}{\mathrm{g} \mathrm{c \textrm {cm } ^ { - 3 }}}$} & \multirow[t]{2}{*}{$\phi$} & \multirow[t]{2}{*}{$\theta^{2}$} & \multirow{2}{*}{$\frac{\mathrm{D}_{\mathrm{s}}}{10^{-6} \mathrm{~cm}^{2} \mathrm{~s}^{-1}}$} \\
\hline & & $\mathrm{g} \mathrm{g}^{-1}$ & $\%$ of WHC & & & & & & \\
\hline Alness 1 & 0.64 & 0.45 & 70.74 & 2.20 & 1.21 & 1.09 & 0.55 & 2.19 & 2.50 \\
\hline Alness 2 & 1.00 & 0.66 & 66.31 & 1.51 & 0.97 & 0.83 & 0.64 & 1.89 & 2.77 \\
\hline Alness 3 & 0.72 & 0.43 & 60.61 & 2.30 & 1.24 & 1.05 & 0.54 & 2.23 & 2.47 \\
\hline Alness 4 & 0.65 & 0.64 & 98.74 & 1.56 & 0.99 & 0.88 & 0.63 & 1.91 & 2.74 \\
\hline Balruddery & 0.67 & 0.47 & 70.03 & 2.14 & 1.20 & 1.01 & 0.56 & 2.17 & 2.52 \\
\hline Banadl & 0.82 & 0.61 & 74.74 & 1.63 & 1.02 & 0.88 & 0.62 & 1.94 & 2.71 \\
\hline Benvie & 0.62 & 0.37 & 59.15 & 2.71 & 1.35 & 1.13 & 0.50 & 2.39 & 2.36 \\
\hline Bicton & 0.53 & 0.39 & 73.09 & 2.58 & 1.32 & 1.13 & 0.51 & 2.34 & 2.39 \\
\hline Bronydd high $\mathrm{P}$ & 0.87 & 0.66 & 76.52 & 1.51 & 0.97 & 0.94 & 0.64 & 1.89 & 2.77 \\
\hline Bronydd low $\mathrm{P}$ & 0.97 & 0.69 & 71.81 & 1.44 & 0.94 & 0.86 & 0.65 & 1.86 & 2.80 \\
\hline Canol & 0.95 & 0.74 & 77.16 & 1.36 & 0.90 & 0.83 & 0.67 & 1.82 & 2.84 \\
\hline Dartmoor & 1.15 & 2.48 & 215.15 & 0.40 & 0.35 & 0.38 & 0.87 & 1.28 & 3.51 \\
\hline De Bathe & 0.58 & 0.38 & 64.87 & 2.64 & 1.33 & 1.23 & 0.51 & 2.36 & 2.38 \\
\hline Dunsdon impr. & 0.77 & 0.60 & 78.47 & 1.66 & 1.03 & 0.97 & 0.62 & 1.96 & 2.70 \\
\hline Dunsdon unimpr. & 0.78 & 0.64 & 81.69 & 1.57 & 0.99 & 0.97 & 0.63 & 1.91 & 2.74 \\
\hline Friockheim 1 & 0.64 & 0.40 & 61.54 & 2.52 & 1.30 & 1.09 & 0.52 & 2.32 & 2.41 \\
\hline Friockheim 2 & 0.64 & 0.39 & 60.64 & 2.57 & 1.32 & 1.09 & 0.51 & 2.34 & 2.39 \\
\hline Haddington 1 & 0.68 & 0.40 & 58.38 & 2.52 & 1.30 & 1.05 & 0.52 & 2.32 & 2.41 \\
\hline Haddington 2 & 0.69 & 0.40 & 57.44 & 2.52 & 1.30 & 1.05 & 0.52 & 2.32 & 2.41 \\
\hline Haddington 3 & 0.67 & 0.39 & 57.81 & 2.57 & 1.32 & 0.97 & 0.51 & 2.34 & 2.39 \\
\hline Haddington 4 & 0.63 & 0.37 & 58.16 & 2.74 & 1.36 & 1.13 & 0.50 & 2.40 & 2.35 \\
\hline King's sedge & 1.24 & 0.98 & 79.65 & 1.02 & 0.74 & 1.01 & 0.73 & 1.64 & 3.03 \\
\hline Rothamsted & 0.51 & 0.36 & 71.23 & 2.74 & 1.36 & 1.35 & 0.50 & 2.40 & 2.35 \\
\hline Rowden & 0.84 & 0.70 & 83.80 & 1.42 & 0.93 & 0.94 & 0.65 & 1.85 & 2.81 \\
\hline Southlake north & 1.03 & 0.95 & 92.24 & 1.05 & 0.76 & 0.94 & 0.72 & 1.66 & 3.01 \\
\hline Southlake south & 0.88 & 0.97 & 110.80 & 1.03 & 0.75 & 0.83 & 0.72 & 1.65 & 3.02 \\
\hline Tayport & 0.51 & 0.36 & 69.49 & 2.81 & 1.38 & 0.83 & 0.49 & 2.43 & 2.33 \\
\hline Tentsmuir & 0.84 & 0.47 & 55.91 & 2.13 & 1.19 & 1.23 & 0.56 & 2.17 & 2.52 \\
\hline Vealand impr. & 1.03 & 0.63 & 61.38 & 1.58 & 1.00 & 0.88 & 0.63 & 1.92 & 2.73 \\
\hline Vealand unimpr. & 0.88 & 0.79 & 89.73 & 1.27 & 0.86 & 0.91 & 0.68 & 1.77 & 2.88 \\
\hline Woburn 1 & 0.48 & 0.45 & 93.55 & 2.21 & 1.21 & 1.35 & 0.55 & 2.20 & 2.50 \\
\hline Woburn 2 & 0.51 & 0.29 & 55.97 & 3.49 & 1.52 & 1.35 & 0.44 & 2.66 & 2.18 \\
\hline
\end{tabular}

${ }^{a} \mathrm{WHC}$, water holding capacity; $\mathrm{P}_{\mathcal{o}}$ particle concentrations: soil dry weight divided by the soil solution volume; $\rho_{\mathrm{s}}$, bulk density of the soil slurry; $\rho_{\mathrm{o}}$, bulk density of the dry soil; $\phi$, soil porosity; $\theta^{2}$, diffusive tortuosity according to Boudreau, $(1996)$; $\mathrm{D}$, diffusive coefficient in soils at $20{ }^{\circ} \mathrm{C}$.

After $24 \mathrm{~h}$ of deployment the DGT and DET devices were removed and rinsed with ultrapure water to remove any adhering soil particles. The ferrihydrite gels from the DGTs and the diffusive gels from the DETs were retrieved and eluted with $2 \mathrm{~mL}$ of $0.25 \mathrm{M} \mathrm{H}_{2} \mathrm{SO}_{4}$ solution overnight before analysis. Three nondeployed DGT and DET “blanks" were prepared concurrently with each deployment and treated identically to the devices deployed on the soil samples. The soil slurry was centrifuged at $5000 \mathrm{rpm}$ for $15 \mathrm{~min}$ in $50 \mathrm{~mL}$ tubes in order to separate the pore water from solid matrix. The concentration of the molybdate-reactive P (inorganic P) in the DGT and DET eluents as well as in the pore water extract $\left(\mathrm{P}_{\mathrm{pw}}\right)$ was measured colorimetrically as described by Murphy and Riley (1962). ${ }^{14}$ The reaction volumes proportionally reduced to a final $240 \mu \mathrm{L}$ in order to be developed in 96 wells microplates and were read on a Multiskan spectrophotometer (Thermo Fisher Scientific Inc., UK). Total phosphorus was measured by inductively coupled plasma mass spectrometry (XSERIES 2 ICP-MS, Thermo Fisher Scientific Inc., Hemel Hempstead, UK) and the molybdate-unreactive P in DGT and DET extracts was estimated as the difference between the total $\mathrm{P}$ and the molybdate-reactive $\mathrm{P}\left(\mathrm{P}_{\mathrm{i}}\right)$; this solution molybdate unreactive $\mathrm{P}$ is hereby termed Po.
Calculation of $\mathrm{P}_{\mathrm{DGT}}, \mathrm{P}_{\mathrm{E}}, K_{\mathrm{d}}, R_{\mathrm{diff}}, X_{\mathrm{sol}}$, and $X_{\mathrm{ads}}$. The concentration of solution $P$ at the surface of the DGT device was calculated using eq 1 according to Zhang and Davison (1995). ${ }^{12}$

$$
\mathrm{P}_{\mathrm{DGT}}=\frac{M \Delta \mathrm{g}}{D A t}
$$

where $M$ is the accumulated P mass in the DGT binding layer, $A$ is the surface area of the DGT sampling window, $t$ is the deployment time, $\Delta \mathrm{g}$ is the total thickness of the diffusive gel layer and the filter membrane, and $D$ is the diffusion coefficient of $\mathrm{P}$ in the diffusive gel. The DGT is a passive sampler and, therefore, results from eq 1 reflect a time-averaged concentration in the soil solution immediately adjacent to the outer surface of the DGT device.

$\mathrm{P}_{\mathrm{DGT}}$ was converted to an effective concentration using eq 2 to represent the effectively available $\mathrm{P}$ from both soil solution and the solid-phase labile pool. ${ }^{10}$

$$
\mathrm{P}_{\mathrm{E}}=\frac{\mathrm{P}_{\mathrm{DGT}}}{R_{\text {diff }}}
$$

$R_{\text {diff }}$ is the hypothetical ratio of the $\mathrm{P}_{\mathrm{DGT}}$ to the concentration in soil solution if no resupply from the solid phase occurred (only pore water P diffusion). $R_{\text {diff }}$ was calculated using the DIFS 
dynamic numerical model of the DGT-soil system. ${ }^{8}$ Input parameters of particle concentration $\left(\mathrm{P}_{c}\right.$; ratio between dry weight and volume of soil solution), soil porosity $(\phi)$, and the diffusion coefficient of $\mathrm{P}$ in the soil $\left(D_{\mathrm{s}}\right)$ were calculated according to Harper et al. (2000). ${ }^{7}$ To simulate "diffusion only" conditions the system response time, $T_{\mathcal{O}}$ was set to $1 \times 10^{10} \mathrm{~s}$ and $\mathrm{K}_{\mathrm{d}}$ was set as $0 \mathrm{~cm}^{3} \mathrm{~g}^{-1}$. While $R$ represents the empirical relative contribution of the system to dynamically maintain the solution concentration adjacent to the DGT device, $R_{\text {diff }}$ is the minimal possible $R$ value in the absence of solid phase resupply (diffusion only). The difference of $R$ and $R_{\text {diff, }}, R-R_{\text {diff, }}$ was used as an estimation of expected dynamic contribution from desorption during the DGT deployment, relative to the original soil solution concentration.

The $R$ ratio was calculated as the mean $\mathrm{P}$ concentration measured by DGT relative to the solution $\mathrm{P}$ concentration measured using DET (eq 3). Assuming that $\mathrm{P}_{\text {Olsen }}$ provides an estimate of the labile solid phase pool, the distribution coefficient between the solid and solution phases $\left(K_{d}\right)$ was calculated as $\mathrm{P}_{\text {Olsen }} / \mathrm{P}_{\mathrm{DGT}}$. The value of $T_{\mathrm{c}}$ derived using DIFS corresponds to the time needed to bring the interfacial concentration of $\mathrm{P}, \mathrm{P}_{\mathrm{i}}$, from 0 to $63 \%$ of its pseudo steady state value. ${ }^{7}$ Assuming that the desorption rate constants are much lower than the sorption rate constant $\left(k_{1} \gg k_{-1}\right)$, the sorption rate constant can be estimated as in eq 4 and the desorption rate constant can be calculated as in eq 5. ${ }^{7,15}$ The estimated desorption rates can therefore be calculated as in eq 6 . The desorption rate constant is independent of DGT deployment time.

$$
\begin{aligned}
& R=\frac{\mathrm{P}_{\mathrm{DGT}}}{\mathrm{P}_{\mathrm{DET}}} \\
& k_{1}=\frac{1}{T_{\mathrm{c}}} \\
& k_{-1}=\frac{k_{1}}{K_{\mathrm{d}} \mathrm{P}_{\mathrm{c}}} \\
& \text { Dspt rate }=\mathrm{P}_{\text {Olsen }} \mathrm{P}_{\mathrm{c}} k_{-1}
\end{aligned}
$$

The distance from the DGT device to which the soil solution $\left(x_{\text {sol }}\right)$ or the adsorbed labile $\mathrm{P}\left(x_{\mathrm{ads}}\right)$ are depleted after $24 \mathrm{~h}$ were also estimated by DIFS model. ${ }^{8}$ The limit to depletion was arbitrarily set on reduction of at least $5 \%$ of solution concentration $\left(x_{\text {sol }}\right)$ or the $5 \%$ of $K_{\mathrm{d}}\left(x_{\mathrm{ads}}\right)$ based on the resolution of the outcome data from the DIFS model, as a standard limit that could be used to compare all the studied soils. Similarly, the dependency of the output $R$ values on time was used to calculate the maximum $R\left(R_{\max }\right)$ and the time at which $R_{\max }$ was reached $\left(T_{\mathrm{Rmax}}\right)$.

The output parameters from the DIFS model ( $R_{\mathrm{diff}}, R_{\max }, x_{\mathrm{ads}}$, $x_{\text {sol }}, T_{c}$ and $\left.T_{\text {Rmax }}\right)$ reflect both the model assumptions and the variation of all empirically determined input data used to run this model, including the DGT and DET measurements at $24 \mathrm{~h}$.

Statistical Methods. Pearson's correlation was used between independent variables and the significance of correlations was judged using standard $t$ test (significant at $p \leq 0.05$ and very significant at $p \leq 0.01$ ). Where necessary, according to results of Andersen-Darling test for normality, data were ln transformed prior to correlation analyses. Nonlinear regression functions (exponential or logarithmic) were fitted to the selected plots in order to draw patterns of general interrelations between parameters. All statistical calculations were performed in Microsoft Excel.

\section{RESULTS}

Phosphorus Availability Indices. The soils used in this study correspond to a wide range of $\mathrm{P}$ status as reflected in the parameters displayed in Table 2. Olsen $P$ averaged $49.1 \mathrm{mg} \mathrm{kg}^{-1}$ and ranged from 5.6 (Tentsmuir site) to 184.4 (Haddington1) $\mathrm{mg} \mathrm{kg}{ }^{-1}$. Olsen $\mathrm{P}$ is related to a regulatory $\mathrm{P}$ index for crop nutrition used in the $\mathrm{UK},{ }^{16}$ which ranges from 0 (insufficient $\mathrm{P}$ supply) to 7 (excessive availability). In the current study, half of the soils analyzed belong to indexes 3 and $4\left(26\right.$ to $\left.70 \mathrm{mg} \mathrm{L}^{-1}\right)$, corresponding to "high" and "very high" available P. The phosphorus effective concentration $\left(\mathrm{P}_{\mathrm{E}}\right)$ is calculated using the measured $\mathrm{P}_{\mathrm{DGT}}$ and calculated $R_{\text {diff. }}$ It accounts for both soil solution $\mathrm{P}$ and easily desorbable $\mathrm{P}$. In our soils, $\mathrm{P}_{\mathrm{E}}$ averaged $2.32 \pm 2.41 \mathrm{mg} \mathrm{L}^{-1}$. The organic soil Dartmoor had a moderate $\mathrm{P}_{\mathrm{Olsen}}$ but a very high iron oxide strip $\mathrm{P}\left(\mathrm{P}_{\mathrm{FeO}}\right), \mathrm{P}_{\mathrm{DGT}}$ and $\mathrm{P}_{\mathrm{E}}$ compared to the other soils in this study. Tentsmuir, the sandy soil, showed a similar pattern, but to a lesser degree, with very low $\mathrm{P}_{\text {Olsen }}\left(5.6 \mathrm{mg} \mathrm{kg}^{-1}\right)$, average $\mathrm{P}_{\mathrm{FeO}}\left(11.4 \mathrm{mg} \mathrm{kg}^{-1}\right)$, and a high $\mathrm{P}_{\text {DGT }}\left(0.35 \mathrm{mg} \mathrm{L}^{-1}\right)$ and $\mathrm{P}_{\mathrm{E}}\left(5.21 \mathrm{mg} \mathrm{L}^{-1}\right)$. Other mineral soils with average physical properties and high $\mathrm{P}_{\text {Olsen }}$, (e.g., Vealand improved, Bicton and Friockheim 1 and 2) contrastingly had low $\mathrm{P}_{\mathrm{DGT}}$ and $\mathrm{P}_{\mathrm{E}}$. In these cases, as for Tentsmuir and Dartmoor soils, $\mathrm{P}_{\mathrm{FeO}}$ appears to be better explaining $\mathrm{P}_{\mathrm{DGT}}$ and $\mathrm{P}_{\mathrm{E}}$ variation than $\mathrm{P}_{\text {Olsen }}$.

Comparing with other common soil $\mathrm{P}$ parameters, $\mathrm{P}_{\mathrm{DGT}}$ was better correlated with $\mathrm{P}_{\mathrm{FeO}}$ strips and several other $\mathrm{P}$ indexes $\left(\mathrm{P}_{\text {water }}, \mathrm{P}_{\mathrm{NaOH} / \mathrm{EDTA}}\right.$, and $\left.\mathrm{P}_{\text {sat }}\right)$ than with $\mathrm{P}_{\text {Olsen }}$ (Table 3). Similarly, $\mathrm{P}_{\mathrm{DET}}$ was better correlated with $\mathrm{P}_{\mathrm{FeO}}$ and $\mathrm{P}_{\text {water }}$ than with other parameters. $K_{\mathrm{d}}$ was poorly correlated with every tested parameter (Table 3). Differences between $\mathrm{P}_{\mathrm{DGT}}$ and $\mathrm{P}$ concentration in soil extracts (e.g., $\mathrm{P}_{\text {water }}$ and $\mathrm{P}_{\text {Olsen }}$ ) certainly reflect the fact that DGT method includes dissimilarities in soil $\mathrm{P}$ diffusion and kinetics of $P$ resupply from solid phase, while $P$ extraction methods just consider equilibrium $\mathrm{P}$ at constant solid to solution ratio. The phosphorus effective concentration $\left(\mathrm{P}_{\mathrm{E}}\right)$ was better correlated with most $\mathrm{P}$ concentrations in soil extracts than $\mathrm{P}_{\mathrm{DGT}}$ (Table 3 ), indicating that this parameter may be a better representation of $\mathrm{P}$ availability than $\mathrm{P}_{\mathrm{DGT}}$ alone.

Organic $\mathrm{P}, \mathrm{P}_{\mathrm{o}}$, was estimated in the DGT and DET extracts as the difference between the total accumulated mass of $\mathrm{P}$ and the mass of molybdate-reactive $\mathrm{P}\left(\mathrm{P}_{\mathrm{i}}\right)$. The $\mathrm{P}_{\mathrm{o}}$ fraction that accumulated in the DGT binding layer averaged $38.9 \pm 12.4 \%$, slightly less than the $43.7 \pm 15.9 \%$ accumulated in the DET diffusive gel. $\mathrm{P}_{\mathrm{o}}$ eluted from the DET gel represents molecules capable of diffusing from soil solution through the filter membrane and the polyacrylamide gel. The proportion of $\mathrm{P}_{\mathrm{o}}$ in the DGT binding layer is based only on the accumulated mass, since the speciation of the numerous $\mathrm{P}_{\mathrm{o}}$ forms and their diffusive coefficients in the diffusive layer are unknown.

Phosphorus Mobility and Resupply from Solid Phase Evaluated by the DIFS Model. The ratio of $\mathrm{P}_{\mathrm{DGT}}$ to $\mathrm{P}_{\mathrm{DET}}(\mathrm{R})$ ranged from 0.08 to 0.36 and corresponded to the contribution of both $\mathrm{P}_{\mathrm{i}}$ diffusion through soil pores and the replenishment of pore water Pi due to its desorption from solid phase (Table 4). The dependency of the $\mathrm{P}_{\mathrm{DET}}$ on $\mathrm{P}_{\mathrm{DGT}}$ followed a log linear pattern (Figure $1 \mathrm{~B}$ ), tending to proportionally reduce increases in $R$ ratios at greater $\mathrm{P}_{\mathrm{DGT}}$ values. The contribution of diffusion $\left(R_{\text {diff }}\right)$ to the accumulated mass was estimated using the DIFS model by setting $K_{\mathrm{d}}$ as 0 and $T_{\mathrm{c}}$ as $1 \times 10^{10} . R_{\text {diff }}$ ranged from 0.05 to 0.12 (Table 4) and was dependent on the amount of water added during the slurry preparation and the resulting porosity, tortuosity and diffusive coefficients in soil (Table 1). 
Table 2. Phosphorus Concentrations in $\mathbf{P}_{\mathrm{Olsen}}, \mathbf{P}_{\mathrm{FeO}}, \mathbf{P}_{\text {water }}$, Soil Pore Water $\left(\mathbf{P}_{\mathrm{pw}}\right), \mathbf{P}_{\mathrm{DGT}}, \mathbf{P}_{\mathrm{DET}}$, and Calculated Effective $\mathbf{P}$ Concentration $\left(\mathbf{P}_{\mathrm{E}}\right)$ in Relation to the Following

\begin{tabular}{|c|c|c|c|c|c|c|c|c|c|c|c|}
\hline \multirow[b]{2}{*}{ soil } & \multirow{2}{*}{$\frac{\mathrm{P}_{\text {Olsen }}{ }^{a}}{\mathrm{mg} \mathrm{kg}^{-1}}$} & \multirow{2}{*}{$\frac{\mathrm{P}_{\mathrm{FeO}}{ }^{a}}{\mathrm{mg} \mathrm{kg}^{-1}}$} & \multirow{2}{*}{$\frac{\mathrm{P}_{\text {water }}{ }^{a}}{\mathrm{mg} \mathrm{kg}^{-1}}$} & \multirow{2}{*}{$\frac{\mathrm{P}_{\mathrm{pw}}{ }^{b}}{\mathrm{mg} \mathrm{L^{-1 }}}$} & \multicolumn{3}{|c|}{$\mathrm{P}_{\mathrm{DGT}}{ }^{c}$} & \multicolumn{3}{|c|}{$\mathrm{P}_{\mathrm{DET}}$} & \multirow{2}{*}{$\frac{\mathrm{P}_{\mathrm{E}}}{\mathrm{mg} \mathrm{L^{-1 }}}$} \\
\hline & & & & & $\mathrm{Pi}\left(\mathrm{mg} \mathrm{L}^{-1}\right)$ & Pi (\%) & Po (\%) & $\mathrm{Pi}\left(\mathrm{mg} \mathrm{L}^{-1}\right)$ & $\mathrm{Pi}(\%)$ & Po (\%) & \\
\hline Alness 1 & 51.3 & 34.5 & 2.7 & 0.80 & $0.14 \pm 0.02$ & 54.6 & 45.4 & $0.93 \pm 0.06$ & 59.5 & 40.5 & 2.11 \\
\hline Alness 2 & 27.7 & 5.7 & 1.5 & 0.65 & $0.07 \pm 0.03$ & 50.9 & 49.1 & $0.66 \pm 0.13$ & 46.3 & 53.7 & 0.84 \\
\hline Alness 3 & 48.8 & 30.9 & 2.7 & 0.44 & $0.10 \pm 0.02$ & 65.0 & 35.0 & $0.86 \pm 0.07$ & 68.2 & 31.8 & 1.57 \\
\hline Alness 4 & 46.1 & 41.1 & 6.0 & 1.24 & $0.31 \pm 0.02$ & 61.1 & 38.9 & $1.16 \pm 0.29$ & 60.4 & 39.6 & 4.01 \\
\hline Balruddery & 60.0 & 40.3 & 1.7 & 0.46 & $0.07 \pm 0.02$ & 50.0 & 50.0 & $0.70 \pm 0.05$ & 49.9 & 50.1 & 1.03 \\
\hline Banadl & 72.7 & 38.2 & 7.6 & 1.51 & $0.15 \pm 0.02$ & 52.5 & 47.5 & $0.75 \pm 0.03$ & 47.2 & 52.8 & 2.00 \\
\hline Benvie & 65.7 & 39.0 & 3.8 & 0.65 & $0.13 \pm 0.01$ & 66.3 & 33.7 & $0.81 \pm 0.02$ & 64.4 & 35.6 & 2.22 \\
\hline Bicton & 80.7 & 49.2 & 9.1 & 1.79 & $0.30 \pm 0.08$ & 65.7 & 34.3 & $1.18 \pm 0.15$ & 79.1 & 20.9 & 5.03 \\
\hline Bronydd high $\mathrm{P}$ & 28.9 & 17.0 & 2.6 & 0.72 & $0.09 \pm 0.01$ & 55.4 & 44.6 & $0.57 \pm 0.10$ & 32.9 & 67.1 & 1.15 \\
\hline Bronydd low P & 9.2 & 8.0 & 1.6 & 0.63 & $0.06 \pm 0.02$ & 43.0 & 57.0 & $0.58 \pm 0.03$ & 31.3 & 68.7 & 0.77 \\
\hline Canol & 25.1 & 17.5 & 2.4 & 0.70 & $0.10 \pm 0.03$ & 63.9 & 36.1 & $0.72 \pm 0.17$ & 41.0 & 59.0 & 1.15 \\
\hline Dartmoor & 28.4 & 108.9 & 31.5 & 1.89 & $0.50 \pm 0.20$ & 70.7 & 29.3 & $2.29 \pm 0.35$ & 88.8 & 11.2 & 4.28 \\
\hline De Bathe & 46.7 & 21.0 & 1.9 & 0.86 & $0.09 \pm 0.03$ & 62.3 & 37.7 & $0.63 \pm 0.20$ & 56.9 & 43.1 & 1.49 \\
\hline Dunsdon impr. & 24.0 & 11.2 & 1.7 & 0.70 & $0.09 \pm 0.02$ & 62.3 & 37.7 & $0.54 \pm 0.11$ & 30.3 & 69.7 & 1.21 \\
\hline Dunsdon unimpr. & 12.4 & 8.9 & 1.0 & 0.19 & $0.09 \pm 0.02$ & 66.0 & 34.0 & $0.50 \pm 0.06$ & 42.3 & 57.7 & 1.10 \\
\hline Friockheim 1 & 72.1 & 47.4 & 3.5 & 0.46 & $0.11 \pm 0.01$ & 53.8 & 46.2 & $1.20 \pm 0.43$ & 70.5 & 29.5 & 1.74 \\
\hline Friockheim 2 & 79.5 & 57.9 & 2.5 & 0.36 & $0.10 \pm 0.01$ & 51.3 & 48.7 & $0.89 \pm 0.02$ & 70.3 & 29.7 & 1.72 \\
\hline Haddington 1 & 184.4 & 139.0 & 12.2 & 1.85 & $0.84 \pm 0.06$ & 82.6 & 17.4 & $2.35 \pm 0.20$ & 77.2 & 22.8 & 13.72 \\
\hline Haddington 2 & 50.7 & 31.9 & 4.1 & 1.85 & $0.09 \pm 0.02$ & 60.8 & 39.2 & $0.76 \pm 0.01$ & 61.1 & 38.9 & 1.55 \\
\hline Haddington 3 & 87.2 & 51.9 & 4.0 & 0.94 & $0.12 \pm 0.01$ & 58.2 & 41.8 & $0.73 \pm 0.14$ & 51.9 & 48.1 & 2.04 \\
\hline Haddington 4 & 42.3 & 23.9 & 3.2 & 1.80 & $0.09 \pm 0.02$ & 66.6 & 33.4 & $0.47 \pm 0.05$ & 47.3 & 52.7 & 1.53 \\
\hline King's sedge & 26.5 & 6.3 & 1.0 & 0.25 & $0.08 \pm 0.01$ & 65.3 & 34.7 & $0.76 \pm 0.01$ & 42.9 & 57.1 & 0.82 \\
\hline Rothamsted & 38.2 & 18.2 & 1.2 & 0.35 & $0.08 \pm 0.01$ & 86.9 & 13.1 & $0.70 \pm 0.11$ & 63.6 & 36.4 & 1.42 \\
\hline Rowden & 43.0 & 34.3 & 1.8 & 0.57 & $0.13 \pm 0.01$ & 93.3 & 6.7 & $0.84 \pm 0.06$ & 60.1 & 39.9 & 1.58 \\
\hline Southlake north & 15.9 & 26.9 & 2.5 & 0.37 & $0.12 \pm 0.02$ & 43.8 & 56.2 & $0.94 \pm 0.19$ & 40.1 & 59.9 & 1.36 \\
\hline Southlake south & 19.3 & 32.8 & 3.0 & 0.68 & $0.11 \pm 0.03$ & 44.4 & 55.6 & $0.92 \pm 0.08$ & 55.6 & 44.4 & 1.19 \\
\hline Tayport & 84.5 & 57.6 & 6.3 & 1.31 & $0.21 \pm 0.02$ & 55.4 & 44.6 & $1.35 \pm 0.01$ & 67.6 & 32.4 & 3.77 \\
\hline Tentsmuir & 5.6 & 11.4 & 4.2 & 1.46 & $0.35 \pm 0.00$ & 77.2 & 22.8 & $1.56 \pm 0.01$ & 80.8 & 19.2 & 5.21 \\
\hline Vealand impr. & 86.8 & 26.9 & 3.5 & 1.10 & $0.08 \pm 0.01$ & 39.7 & 60.3 & $0.46 \pm 0.08$ & 29.6 & 70.4 & 1.09 \\
\hline Vealand unimpr. & 18.7 & 21.8 & 4.5 & 0.43 & $0.10 \pm 0.01$ & 53.3 & 46.7 & $0.60 \pm 0.15$ & 42.2 & 57.8 & 1.23 \\
\hline Woburn 1 & 25.4 & 8.3 & 0.5 & 0.08 & $0.07 \pm 0.01$ & 69.6 & 30.4 & $0.91 \pm 0.22$ & 76.5 & 23.5 & 1.14 \\
\hline Woburn 2 & 63.1 & 45.9 & 6.4 & 0.43 & $0.16 \pm 0.04$ & 64.2 & 35.8 & $1.05 \pm 0.01$ & 64.6 & 35.4 & 3.15 \\
\hline
\end{tabular}

${ }^{a} \mathrm{Pi}$ in different extractants, data published in Stutter et al. (2015). ${ }^{b} \mathrm{P}$ concentration in soil pore water extracted by two cycles centrifugation of the slurry in which DGTs where deployed. ${ }^{c} \%$ values refer to difference of total P mass accumulated in the gel and does not account for differences in diffusive coefficients.

The difference between $R$ and $R_{\text {diff }}$ is a quantitative measurement of the ability of each soil to resupply $P_{i}$ to the pore water in response to DGT-induced depletion. The $T_{c}$ and desorption rate showed a tighter fit to $R-R_{\text {diff }}$ (Figure $1 \mathrm{E}$ and $1 \mathrm{~F}$ ) than to the $R$ ratio likely due to the variability of soil wetting parameters and their influence on the $R_{\text {diff }}$ values.

The maximum distance of pore water depletion $\left(X_{\mathrm{sol}}\right)$ averaged $0.42 \pm 0.10 \mathrm{~cm}$ and for the desorbable $P_{i}$ concentration the maximum distance of depletion $\left(X_{\mathrm{ads}}\right)$ averaged $0.36 \pm$ $0.07 \mathrm{~cm}$. The distance of depletion represents the maxim distance where roots can influence soil $\mathrm{P}$ concentrations.

The $P_{i}$ concentration at the surface of the DGT is time dependent and the $R$ values peak at $R_{\max }$ at $T_{\mathrm{Rmax}}$ seconds after the deployment begins (Figure 1A). By analyzing the shape of $R$-time dependency, two patterns emerge. The most common pattern is the case in which the $R$ values peak $\left(R_{\max }\right)$ at $T_{\mathrm{Rmax}}$ (between 20 and $50 \mathrm{~min}$ ) and decrease to equilibrium near constant value after $10 \mathrm{~h}$ (Figure 1A). Alternatively, some soils do not display this peak and do not reach a constant $R$ until after $24 \mathrm{~h}$ (e.g., Tentsmuir and Dartmoor; Figure 1A). $R_{\max }$ appears to be a function of porosity (and therefore $C_{\text {org }}$ concentration), with the exception of the outliers Tentsmuir and Haddington 1.
The difference $R_{\max }-R$ is a direct negative proportion of $R-R_{\text {diff, }}$ in other words, with increasing resupply capacity of the soil $\left(R-R_{\text {diff }}\right)$ the $R$ curve in time will become less peak-shaped (low $R_{\max }-R$; Figure 1D). While the relative $\mathrm{P}_{\mathrm{i}}$ flux response in the first hour is mainly influenced by soil wetting properties, at longer time it tends to be a function of the resupply capacity $\left(R-R_{\text {diff }}\right)$ of the soil solid phase (Figure 1D and F). This behavior as well as the shape of the time series curves of the $R$ ratio reflects both the DIFS model assumptions ${ }^{7,8}$ and the variability of input parameters, specific for the used soil samples. The system response time $\left(T_{c}\right)$ is very sensitive to variations in the input values for $R$ in the DIFS model. Therefore, absolute values must be interpreted with caution due to the effects of possible accumulated errors. $T_{\mathrm{c}}$ values showed a log-normal distribution and were found to be $\log$-linear with respect to $R-R_{\text {diff, }}$ exponentially decaying with increasing $R-R_{\text {diff }}$ values (Figure $1 \mathrm{E}$ ). $T_{\mathrm{c}}$ values averaged $3.63 \mathrm{~h}$ (considering the log transformations), and ranged from $0.038 \mathrm{~s}$ in Tentsmuir to $88 \mathrm{~h}$ in King's sedge soils.

In the (de)sorption rate constant analysis, Tentsmuir was a clear outlier with low $T_{\mathrm{c}}$ and very high $k_{1}$ and $\mathrm{k}_{-1}$ values, and was therefore excluded from the trend line analysis of Figures 1 
Table 3. Pearson Correlation Coefficient of Experimental Soil Parameters, DGT, DET, and DIFS Calculated Parameters ${ }^{a}$

\begin{tabular}{|c|c|c|c|c|c|c|c|c|c|c|c|c|c|c|}
\hline & $\mathrm{P}_{\mathrm{pw}}$ & $\mathrm{P}_{\mathrm{DGT}}$ & $\mathrm{P}_{\mathrm{DET}}$ & $P_{E}$ & $K_{\mathrm{d}}$ & $R$ & $R_{\text {diff }}$ & $R-R_{\text {diff }}$ & $R_{\max }$ & $T_{\mathrm{Rmax}}$ & $\operatorname{Ln} T_{c}$ & $k_{1}$ & $k_{-1}$ & Dspt rate ${ }^{b}$ \\
\hline surface area & 0.10 & 0.05 & -0.11 & 0.19 & 0.39 & 0.05 & -0.49 & 0.16 & -0.35 & 0.41 & -0.28 & 0.41 & -0.22 & 0.42 \\
\hline clay & 0.18 & 0.13 & -0.02 & 0.28 & 0.38 & 0.11 & -0.57 & 0.24 & -0.40 & 0.45 & -0.35 & 0.46 & -0.16 & 0.48 \\
\hline $\mathrm{C}_{\text {Org }}$ & 0.14 & 0.26 & 0.40 & 0.00 & -0.24 & 0.06 & 0.83 & -0.14 & 0.70 & -0.07 & 0.23 & -0.13 & 0.71 & -0.09 \\
\hline $\mathrm{P}_{\text {Olsen }}$ & 0.40 & 0.57 & 0.43 & 0.69 & 0.27 & 0.51 & -0.48 & 0.61 & -0.19 & 0.72 & -0.64 & 0.78 & 0.10 & 0.76 \\
\hline $\mathrm{P}_{\mathrm{FeO}}$ & 0.53 & 0.83 & 0.82 & 0.78 & 0.07 & 0.61 & -0.02 & 0.60 & 0.21 & 0.69 & -0.60 & 0.71 & 0.63 & 0.71 \\
\hline$P_{o x}$ & 0.33 & 0.57 & 0.41 & 0.68 & 0.20 & 0.47 & -0.30 & 0.53 & 0.02 & 0.82 & -0.47 & 0.77 & 0.04 & 0.77 \\
\hline$P_{\text {sat }}$ & 0.42 & 0.60 & 0.50 & 0.73 & 0.20 & 0.52 & -0.58 & 0.64 & -0.30 & 0.67 & -0.65 & 0.73 & 0.09 & 0.71 \\
\hline $\mathrm{P}_{\mathrm{NaOH} / \mathrm{EDTA}}$ & 0.40 & 0.65 & 0.50 & 0.76 & 0.24 & 0.52 & -0.38 & 0.60 & -0.05 & 0.84 & -0.55 & 0.81 & 0.13 & 0.81 \\
\hline $\mathrm{P}_{\text {tot-fusion }}$ & 0.39 & 0.57 & 0.39 & 0.59 & 0.02 & 0.49 & 0.03 & 0.46 & 0.30 & 0.76 & -0.43 & 0.70 & 0.28 & 0.73 \\
\hline $\mathrm{P}_{\text {water }}$ & 0.61 & 0.69 & 0.77 & 0.51 & -0.23 & 0.53 & 0.39 & 0.42 & 0.43 & 0.29 & -0.42 & 0.35 & 0.93 & 0.37 \\
\hline $\mathrm{P}_{\mathrm{pw}}$ & 1.00 & 0.62 & 0.50 & 0.57 & -0.51 & 0.70 & -0.03 & 0.69 & 0.11 & 0.38 & -0.67 & 0.56 & 0.64 & 0.59 \\
\hline
\end{tabular}

${ }^{a}$ Gray shade intensity is used as a visual aid that indicates how high $\mathrm{r}$ values are, ranging from white at 0.00 to maximum shade at 1.00 or -1.00 . $r$ values over 0.35 are significant $(p \leq 0.05)$ and over 0.45 are very significant $(p \leq 0.01)$ using Student's $t$ test. All parameters listed in the columns are original from this study, whereas surface area, clay, $\mathrm{C}_{\mathrm{Org}}, \mathrm{P}_{\mathrm{Olsen}}, \mathrm{P}_{\mathrm{FeO}}, \mathrm{P}_{\mathrm{ox}}, \mathrm{P}_{\mathrm{sat}} \mathrm{P}_{\mathrm{NaOH} / \mathrm{EDTA}}, \mathrm{P}_{\text {tot-fusion }}$ and $\mathrm{P}_{\text {water }}$ were determined by Stutter et al. $(2015)^{3} .{ }^{b}$ Dspt rate-desorption rate in $\mathrm{mg}$ of $\mathrm{P}$ per litter of soil solution per second.

Table 4. DIFS Derived Parameters Reflecting P Depletion from Soil Pore Water by DGTs, Soil P Diffusion and Kinetics of P Resupply from Soil Solid Matrix

\begin{tabular}{|c|c|c|c|c|c|c|c|c|c|c|c|c|}
\hline & $X_{\text {sol }}$ & $X_{\text {ads }}$ & $K_{\mathrm{d}}$ & $R$ & $R_{\text {diff }}$ & $R-R_{\text {diff }}$ & $R_{\max }$ & $T_{\mathrm{Rmax}}$ & $T_{\mathrm{c}}$ & $k_{1}$ & $k_{-1}$ & Dspt rate ${ }^{a}$ \\
\hline soil & $\mathrm{cm}$ & $\mathrm{cm}$ & $\mathrm{cm}^{3} \mathrm{~g}^{-1}$ & & & & & $10^{3} \mathrm{~s}$ & $\mathrm{~s}$ & $\mathrm{~s}^{-1}$ & $s^{-1}$ & $\mathrm{mg} \mathrm{L}^{-1} \mathrm{~s}^{-1}$ \\
\hline Alness 1 & 0.54 & 0.50 & 64.45 & 0.15 & 0.07 & 0.08 & 0.27 & 1.66 & $1.39 \times 10^{4}$ & $7.21 \times 10^{-5}$ & $5.08 \times 10^{-7}$ & $5.74 \times 10^{-5}$ \\
\hline Alness 2 & 0.57 & 0.45 & 42.51 & 0.10 & 0.08 & 0.02 & 0.32 & 1.33 & $9.98 \times 10^{4}$ & $1.00 \times 10^{-5}$ & $1.56 \times 10^{-7}$ & $6.53 \times 10^{-6}$ \\
\hline Alness 3 & 0.45 & 0.31 & 111.98 & 0.12 & 0.06 & 0.05 & 0.31 & 1.33 & $4.42 \times 10^{4}$ & $2.26 \times 10^{-5}$ & $8.76 \times 10^{-8}$ & $9.85 \times 10^{-6}$ \\
\hline Alness 4 & 0.33 & 0.33 & 37.32 & 0.27 & 0.08 & 0.19 & 0.33 & 2.37 & $3.72 \times 10^{3}$ & $2.69 \times 10^{-4}$ & $4.63 \times 10^{-6}$ & $3.32 \times 10^{-4}$ \\
\hline Balruddery & 0.48 & 0.37 & 129.89 & 0.10 & 0.07 & 0.03 & 0.29 & 1.33 & $5.54 \times 10^{4}$ & $1.80 \times 10^{-5}$ & $6.48 \times 10^{-8}$ & $8.33 \times 10^{-6}$ \\
\hline Banadl & 0.44 & 0.44 & 48.24 & 0.20 & 0.08 & 0.13 & 0.31 & 1.91 & $8.35 \times 10^{3}$ & $1.20 \times 10^{-4}$ & $1.52 \times 10^{-6}$ & $1.80 \times 10^{-4}$ \\
\hline Benvie & 0.42 & 0.37 & 100.39 & 0.16 & 0.06 & 0.10 & 0.26 & 1.66 & $8.96 \times 10^{3}$ & $1.12 \times 10^{-4}$ & $4.10 \times 10^{-7}$ & $7.30 \times 10^{-5}$ \\
\hline Bicton & 0.47 & 0.47 & 45.01 & 0.26 & 0.06 & 0.20 & 0.29 & 2.94 & $2.30 \times 10^{3}$ & $4.35 \times 10^{-4}$ & $3.74 \times 10^{-6}$ & $7.80 \times 10^{-4}$ \\
\hline Bronydd high $\mathrm{P}$ & 0.35 & 0.32 & 40.34 & 0.16 & 0.08 & 0.08 & 0.33 & 1.43 & $2.06 \times 10^{4}$ & $4.86 \times 10^{-5}$ & $8.00 \times 10^{-7}$ & $3.48 \times 10^{-5}$ \\
\hline Bronydd low P & 0.55 & 0.44 & 14.55 & 0.11 & 0.08 & 0.03 & 0.32 & 1.33 & $7.97 \times 10^{4}$ & $1.25 \times 10^{-5}$ & $5.98 \times 10^{-7}$ & $7.93 \times 10^{-6}$ \\
\hline Canol & 0.47 & 0.38 & 35.60 & 0.13 & 0.08 & 0.05 & 0.33 & 1.43 & $4.06 \times 10^{4}$ & $2.46 \times 10^{-5}$ & $5.09 \times 10^{-7}$ & $1.74 \times 10^{-5}$ \\
\hline Dartmoor & 0.39 & 0.36 & 15.03 & 0.22 & 0.12 & 0.10 & 0.41 & 1.77 & $1.30 \times 10^{4}$ & $7.68 \times 10^{-5}$ & $1.27 \times 10^{-5}$ & $1.45 \times 10^{-4}$ \\
\hline De Bathe & 0.28 & 0.27 & 54.15 & 0.14 & 0.06 & 0.08 & 0.28 & 1.43 & $1.57 \times 10^{4}$ & $6.39 \times 10^{-5}$ & $4.47 \times 10^{-7}$ & $5.51 \times 10^{-5}$ \\
\hline Dunsdon impr. & 0.29 & 0.28 & 34.43 & 0.17 & 0.08 & 0.09 & 0.32 & 1.43 & $1.51 \times 10^{4}$ & $6.63 \times 10^{-5}$ & $1.16 \times 10^{-6}$ & $4.62 \times 10^{-5}$ \\
\hline Dunsdon unimpr. & 0.30 & 0.29 & 65.80 & 0.17 & 0.08 & 0.09 & 0.32 & 1.54 & $1.61 \times 10^{4}$ & $6.20 \times 10^{-5}$ & $6.02 \times 10^{-7}$ & $1.17 \times 10^{-5}$ \\
\hline Friockheim 1 & 0.48 & 0.23 & 157.93 & 0.09 & 0.06 & 0.03 & 0.28 & 1.24 & $6.00 \times 10^{4}$ & $1.67 \times 10^{-5}$ & $4.18 \times 10^{-8}$ & $7.61 \times 10^{-6}$ \\
\hline Friockheim 2 & 0.35 & 0.42 & 221.17 & 0.12 & 0.06 & 0.06 & 0.27 & 1.33 & $2.46 \times 10^{4}$ & $4.07 \times 10^{-5}$ & $7.17 \times 10^{-8}$ & $1.46 \times 10^{-5}$ \\
\hline Haddington 1 & 0.29 & 0.32 & 99.50 & 0.36 & 0.06 & 0.30 & 0.37 & 20.9 & $9.98 \times 10^{2}$ & $1.00 \times 10^{-3}$ & $4.00 \times 10^{-6}$ & $1.85 \times 10^{-3}$ \\
\hline Haddington 2 & 0.33 & 0.29 & 27.37 & 0.12 & 0.06 & 0.06 & 0.28 & 1.24 & $2.06 \times 10^{4}$ & $4.85 \times 10^{-5}$ & $7.05 \times 10^{-7}$ & $8.99 \times 10^{-5}$ \\
\hline Haddington 3 & 0.41 & 0.38 & 92.60 & 0.17 & 0.06 & 0.11 & 0.26 & 1.77 & $8.36 \times 10^{3}$ & $1.20 \times 10^{-4}$ & $5.02 \times 10^{-7}$ & $1.13 \times 10^{-4}$ \\
\hline Haddington 4 & 0.35 & 0.35 & 23.53 & 0.19 & 0.06 & 0.13 & 0.26 & 1.77 & $5.71 \times 10^{3}$ & $1.75 \times 10^{-4}$ & $2.72 \times 10^{-6}$ & $3.15 \times 10^{-4}$ \\
\hline King's sedge & 0.66 & 0.49 & 104.55 & 0.10 & 0.09 & 0.01 & 0.35 & 1.54 & $3.17 \times 10^{5}$ & $3.15 \times 10^{-6}$ & $2.97 \times 10^{-8}$ & $8.00 \times 10^{-7}$ \\
\hline Rothamsted & 0.32 & 0.33 & 108.25 & 0.12 & 0.06 & 0.06 & 0.27 & 1.33 & $2.16 \times 10^{4}$ & $4.64 \times 10^{-5}$ & $1.56 \times 10^{-7}$ & $1.64 \times 10^{-5}$ \\
\hline Rowden & 0.37 & 0.34 & 75.90 & 0.15 & 0.08 & 0.07 & 0.33 & 1.43 & $2.43 \times 10^{4}$ & $4.12 \times 10^{-5}$ & $3.82 \times 10^{-7}$ & $2.34 \times 10^{-5}$ \\
\hline Southlake north & 0.52 & 0.43 & 42.65 & 0.13 & 0.09 & 0.04 & 0.35 & 1.54 & $5.37 \times 10^{4}$ & $1.86 \times 10^{-5}$ & $4.15 \times 10^{-7}$ & $6.95 \times 10^{-6}$ \\
\hline Southlake south & 0.58 & 0.46 & 28.41 & 0.12 & 0.09 & 0.03 & 0.35 & 1.54 & $8.26 \times 10^{4}$ & $1.21 \times 10^{-5}$ & $4.14 \times 10^{-7}$ & $8.22 \times 10^{-6}$ \\
\hline Tayport & 0.41 & 0.38 & 64.64 & 0.16 & 0.06 & 0.10 & 0.25 & 1.66 & $8.53 \times 10^{3}$ & $1.17 \times 10^{-4}$ & $6.45 \times 10^{-7}$ & $1.53 \times 10^{-4}$ \\
\hline Tentsmuir & 0.39 & 0.38 & 3.84 & 0.22 & 0.07 & 0.16 & 0.64 & 1.77 & $3.87 \times 10^{-2}$ & $2.58 \times 10^{1}$ & $3.15 \times 10^{0}$ & $3.76 \times 10^{1}$ \\
\hline Vealand impr. & 0.28 & 0.27 & 78.95 & 0.18 & 0.08 & 0.11 & 0.33 & 1.54 & $1.37 \times 10^{4}$ & $7.32 \times 10^{-5}$ & $5.86 \times 10^{-7}$ & $8.05 \times 10^{-5}$ \\
\hline Vealand unimpr. & 0.32 & 0.31 & 43.30 & 0.18 & 0.09 & 0.09 & 0.34 & 1.54 & $1.83 \times 10^{4}$ & $5.46 \times 10^{-5}$ & $9.90 \times 10^{-7}$ & $2.36 \times 10^{-5}$ \\
\hline Woburn 1 & 0.55 & 0.26 & 302.73 & 0.08 & 0.07 & 0.02 & 0.29 & 1.24 & $1.10 \times 10^{5}$ & $9.13 \times 10^{-6}$ & $1.37 \times 10^{-8}$ & $7.66 \times 10^{-7}$ \\
\hline Woburn 2 & 0.38 & 0.38 & 147.97 & 0.15 & 0.05 & 0.10 & 0.23 & 1.66 & $7.85 \times 10^{3}$ & $1.27 \times 10^{-4}$ & $2.47 \times 10^{-7}$ & $5.44 \times 10^{-5}$ \\
\hline
\end{tabular}

${ }^{a}$ Dspt rate-desorption rate in $\mathrm{mg}$ of $\mathrm{P}$ per liter of soil solution per second.

(C, D, E, and F). For the other soils, sorption rate constants $\left(k_{1}\right)$ averaged $1.07 \times 10^{-04} \mathrm{~s}$, whereas $k_{-1}$ values averaged $1.29 \times$ $10^{-06} \mathrm{~s}, k_{1}$ was, as expected, on average 83 fold greater than $k_{-1}$. The estimated $\mathrm{P}_{\mathrm{i}}$ desorption rates during depletion by DGTs averaged $4.71 \mathrm{nmol} \mathrm{L}^{-1} \mathrm{~s}^{-1}$, and was found to exponentially increase with increasing resupply capacity of the soils (calculated as $R-R_{\text {diff; }}$ Figure $\left.1 \mathrm{~F}\right)$.

The maximum response $\left(R_{\max }\right)$ is highly correlated to $C_{\text {Org }}$ and other parameters influenced by $C_{\mathrm{Org}}$, which indicates that it affects the rate of desorption. $C_{\text {Org }}$ was also strongly correlated 

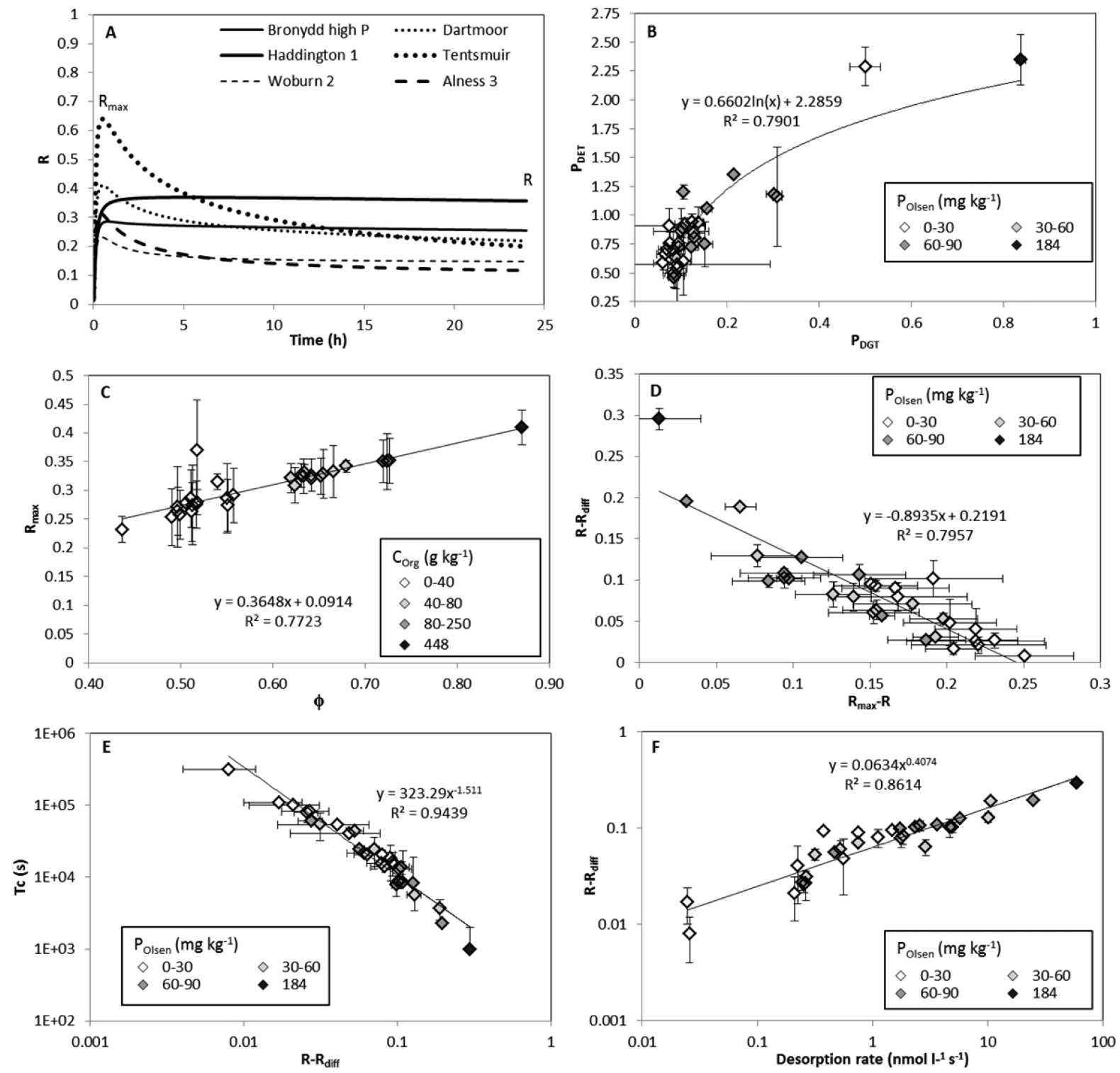

Figure 1. Patterns and interrelations in $P_{\mathrm{i}}$ resupply analysis using DIFS model: (A) Sample of different time dependency of $R$ shaped curves; (B) $R$ ratio as a function of $\mathrm{P}_{\mathrm{DGT}}$; (C) Peak $\mathrm{R}\left(R_{\max }\right)$ as a function of soil porosity $\phi$; (D) Size of the peak $\mathrm{R}\left(R_{\max }-R\right)$ as a function of soil $\mathrm{P}_{\mathrm{i}}$ resupply capacity $\left(R-R_{\text {diff }}\right) ;(E)$ Equilibration time $\left(T_{\mathrm{c}}\right)$ as a function of soil $\mathrm{P}_{\mathrm{i}}$ resupply capacity $\left(R-R_{\text {diff }}\right) ;(\mathrm{D})$ Desorption rates as a function of soil $\mathrm{P}_{\mathrm{i}}$ resupply capacity $\left(R-R_{\text {diff }}\right)$. Error bars represent \pm one standard deviation.

with all wetting parameters (data not shown) and their related soil $\mathrm{P}$ mobility parameters $\mathrm{R}_{\text {diff }}$ and $R_{\mathrm{Max}}$ (Table 3 ). The effect of $C_{\text {Org }}$ was clearly greater than the effect of surface area and particle size distribution, which were not strongly correlated with any $\mathrm{P}$ related soil property.

The $\ln T \mathrm{c}, \mathrm{k} 1$, and the desorption rate showed similar patterns, showing good correlations with $\mathrm{P}$ concentration in soil extracts (except for $\left.\mathrm{P}_{\text {water }}\right)$. Desorption rate constant $\left(k_{-1}\right)$ was highly correlated with $\mathrm{P}_{\text {water }}$ and moderately correlated with $\mathrm{P}_{\mathrm{FeO}}$, $\mathrm{P}_{\mathrm{pw}}, \mathrm{P}_{\mathrm{DGT}}, \mathrm{P}_{\mathrm{DET}}$, and $R$ (Table 3 ). In general, all correlation coefficients for the $\mathrm{P}$ mobility and resupply parameters were improved when the sandy soil Tentsmuir was removed from the data set. The organic soil Dartmoor also behaved as an outlier in a few cases.

\section{DISCUSSION}

The DGT Methodological Approach: Advantages, Issues and Possible Improvements. The combined DGT and DET techniques, and the DIFS model, have been previously applied to estimate the mobility and resupply parameters of soils for metal contaminants, ${ }^{10}$ but has not yet been used to study soil phosphorus. The data set here presented is therefore a unique opportunity to discuss the methodological issues involved, along with the behavior and drivers of the variation of the evaluated parameters.

The effective concentration $\left(\mathrm{P}_{\mathrm{E}}\right)$ is a hypothetical concentration that represents the concentration of $\mathrm{P}$ in the soil pore water if resupply was only dependent on diffusion. Under the assumption of diffusion only, there would be no resupply of $\mathrm{P}$ from the solid phase. This approach is useful for representing, in the same parameter, both the equilibrium soil solution concentration and the easily desorbable/soluble $\mathrm{P}$ forms. ${ }^{9,10}$ The conversion of $\mathrm{P}_{\mathrm{DGT}}$ to $\mathrm{P}_{\mathrm{E}}$ using $R_{\text {diff }}$ depends solely on the amount of water that is added to the slurry preparation (and the final porosity), which is set to a maximum for the soils used in this study. This maximum water retention in the slurry was shown to 
be highly dependent on the organic matter content of the soils. The use of the DIFS model to estimate the soil specific $R_{\text {diff }}$ is still useful, as illustrated by its strong variation and the higher correlation of most of the extractable $\mathrm{P}$ concentrations with $\mathrm{P}_{\mathrm{E}}$ than with $\mathrm{P}_{\mathrm{DGT}}$ (Table 3 ). Additionally to the $R_{\text {diff }}$ the wetting conditions and resulting porosity were clearly influencing the short-term (30-50 $\mathrm{min}$ ) response in the fluxes into the DGT, reflected in the $R_{\max }$ parameter (Figure 1C). Soil structure is completely lost during slurry preparation and in undisturbed conditions, aggregate size has been demonstrated to influence both wetting properties and $\mathrm{P}$ desorption. ${ }^{17}$ The effect of moisture content and soil structure on $\theta^{2}, D_{s}, R_{\text {diff }} T_{\mathcal{O}}$ and $K_{-1}$ needs to be further studied.

Differences between $\mathrm{P}$ concentrations in water extracts $\left(1: 4 \mathrm{w} / \mathrm{v} ; \mathrm{P}_{\text {water }}\right)$, and in soil pore water $\left(\mathrm{P}_{\mathrm{pw}}\right)$ in the equilibrated slurry can be explained by the huge differences in solid: liquid ratio, extraction time and the amount of color interference during the $\mathrm{P}_{\mathrm{i}}$ spectrophotometric determination. Methodologically, the DET preparation returned a much cleaner sample than pore water and water extracts and therefore a more accurate colorimetric determination of $\mathrm{P}_{\mathrm{i}}$. Additionally, the filter membrane and the polyacrylamide gel exert a size exclusion factor, which is likely to contribute to $\mathrm{P}_{\mathrm{DET}}$ having a different pattern of values than those observed for $P_{w a t e r}$ and $P_{p w}$. The same size exclusion factor is present for the DGT, since the same filter membrane and the diffusive gels are used. Therefore, we consider $\mathrm{P}_{\mathrm{DET}}$ to be the most appropriate measurement of soil pore water concentration when it is compared to DGT measurements and these values have been used to calculate the ratio $R$ shown in Table 4. Furthermore, $P_{\mathrm{DGT}}$ showed a higher correlation with $P_{\mathrm{DET}}$ than with $P_{\mathrm{pw}}$, which supports the previously stated (Table 3 ).

DGT and DET extracts maintain limited contamination from the soil matrix due to the size exclusion factor, and less interference is observed in color development by Murphy and Riley $(1962)^{14}$ method, represented by smaller background levels in controls. Color development artifacts in wet chemistry $\mathrm{P}$ determination may be significantly large, especially for water based extracts $\left(\mathrm{P}_{\text {water }}\right.$ and $\left.\mathrm{P}_{\mathrm{pw}}\right)$, where the concentrations are lower and therefore unsuitable for dilutions (Dr. Jane Hawkins, personal communication, December 3, 2014). For these extracts the total phosphorus measured by ICP-MS is a much more accurate parameter, but cannot be used in DGT calculations since organic $\mathrm{P}$ forms are abundantly present in soil extracts and in the eluates from the DGT ferrihydrite binding layer. Each one of the dozens of different organic $P$ forms has its own unique diffusive coefficients in the DGT diffusive layer, needed to calculate their unique $C_{\mathrm{DGT}}$ and $C_{\mathrm{E}}$. Enzyme hydrolysis and HPLC methods may be suitable for further studying the differential behavior of different organic P forms in soils using DGTs.

The use of DGT, DET, and the DIFS model are accurate and practical tools for the study of soil P mobility and resupply from solid phase. The theoretical basis of the DGT assay, which can be related to $P$ uptake by plant roots, as well as the additional parameter estimates gained through the method (e.g., $\mathrm{P}_{\mathrm{E}}, R-R_{\text {diff, }} R_{\text {diff }}$ ) represent significant improvements to typical extract-based soil $P$ tests (e.g., Olsen P). Namely we here propose the use of the $R-R_{\text {diff }}$ value as the soil test parameter that best shows the $P$ resupply from the soil solid phase.

More broadly, the holistic approach taken to resolve phosphorus mobility in soils brings a better understanding and new insights into $\mathrm{P}$ exchange and release kinetics of $\mathrm{P}$ from solid phase to solution. The further use of this method for soils treated in controlled experimental conditions (e.g., use of amendments, fertilizers and high salinity irrigation waters) or in particular sample sets (e.g., chronosequence, slope and other field gradients) will allow the re-examination of old assumptions under a new light and with increased detail.

Further work is needed in order to fit the DIFS model using repeated experimental $R$ values at increasing times of exposure, such as the studies performed by Ernstberger et al. (2002, 2005) for $\mathrm{Cd}, \mathrm{Cu}, \mathrm{Ni}$, and $\mathrm{Zn} .{ }^{18,19}$ This analysis will allow further verifying the accuracy of our estimation of $K_{d}$ as the ratio of $\mathrm{P}_{\text {Olsen }}$ to $\mathrm{P}_{\mathrm{DET}}$.

Implications for Plant Phosphorus Bioavailability. The $\mathrm{P}$ availability for plants depends on its speciation in soil. The $\mathrm{P}$ sorption on the soil solid phase is represented by the solid/liquid $\mathrm{P}_{\mathrm{i}}$ distribution coefficient $\left(K_{\mathrm{d}}\right)$. In this study $K_{\mathrm{d}}$ was calculated as the ratio between $\mathrm{P}_{\mathrm{Olsen}}$ and $\mathrm{P}_{\mathrm{pw}}$, as the $\mathrm{P}_{\text {Olsen }}$ is currently the most used as the best accepted representation of labile adsorbed $\mathrm{P}$ in soils. Nevertheless there is not a consensus for the use of $\mathrm{P}_{\mathrm{Olse}}$ for estimating labile $\mathrm{P}$ even after decades of related research, ${ }^{20}$ and many other extracts have been proposed as $\mathrm{P}$ bioavailability indicators in soils such as, Mehlich 1, Bray 1, Mehlich 3, water, ammonium acetate, and DTPA. ${ }^{21}$ Moreover, many $\mathrm{P}$ indices that employ a strong chemical extractant, were not introduced as a quantitative measure of $\mathrm{P}$ availability, but as availability indexes. For lack of better methods, these are often used as a quantitative measure of plant available P. In some cases the different extractants have been theoretically designed to work with the dominant soil matrix and $\mathrm{pH}$ of specific geographical regions (e.g., alkaline calcareous soils), others are unspecific respect to type of soil matrix. Some of these P bioavailability methods are currently being used and recommended to soils with conditions fundamentally different than the ones these methods were designed for. Ultimately, the greatest challenge for predicting the availability of soil $\mathrm{P}$ to plants will be the design of an easily implemented analytical tool, which best represents the P bioavailability regarding both the residual soil $\mathrm{P}$ and plant response to fertilization. In a critical $\mathrm{P}$ experiment (crop response to increasing $\mathrm{P}$ fertilizer doses) $\mathrm{P}_{\mathrm{DGT}}$ was shown to be the best predictor of maize $\mathrm{P}$ uptake compared to $\mathrm{P}_{\mathrm{Olsen}}$, anion exchange membrane $\mathrm{P}$, oxalate extractable $\mathrm{P}$, Colwell, Bray-1, Mehlich-3 and $\mathrm{CaCl}_{2}-\mathrm{P}$, but not as good at predicting rice $\mathrm{P}$ uptake. ${ }^{22}$

The used two pool model (labile and nonlabile P) is an oversimplification, and many different adsorbed, precipitated and organic forms are more likely to occur. The separation of the labile pool into weak and strong binding sites has been proposed, nevertheless with the available data this is over parametrization. ${ }^{23}$ The majority of the $\mathrm{P}$ associated with the soil solid phase is nonlabile during the $24 \mathrm{~h}$ of the DGT deployment. ${ }^{6}$ In this binary model approach, $K_{\mathrm{d}}$ should account for the easily desorbable and readily soluble forms of inorganic $P$, assuming that no significant contributions of organic $P$ mineralization would take place in this short period. Although in our study we did not have an accurate estimation of this labile pool, the actual $K_{\mathrm{d}}$ can be estimated by regression of a time series of DGT measurements. ${ }^{24}$ This analysis would help to elucidate the real resupply potential of the soils and which extractant reflects more accurately the absolute values of the labile $\mathrm{P}$ forms therein. The estimation of Pi $K_{d}$ using time series DGT analysis should be further studied in future experiments.

The DGT method samples soil solution P and a small fraction of solid phase P desorbed into soil solution by the DGT device perturbing the equilibrium condition. ${ }^{12,22}$ Plants on the other hand, are active mobilizers of soil adsorbed $\mathrm{P}$, using many different mechanisms to induce $\mathrm{P}$ desorption, like root exudation 
of organic acids, siderophores, enzymes, surfactants, and microbial growth stimulants. ${ }^{2,25,26}$ It is expected that these exudates will change the balance between adsorbed and solution $\mathrm{P}$, reducing $K_{\mathrm{d}}$ and increasing $T_{\mathcal{c}}$ after the induced desorption of labile P has occurred. This effect should be dependent on the type (or combination of types) and dose of the exudate, as well as their indirect effect as microbial growth stimulants. Therefore, a realistic indicator of plant available $\mathrm{P}$ will depend both on the labile $\mathrm{P}$ concentration and the plant mechanisms involved in $\mathrm{P}$ mobilization, making the agronomical $K_{\mathrm{d}}$ a crop dependent parameter. Future work on how plant exudates interfere with solid phase resupply using DGT and DET analysis would give quantitative information on active $\mathrm{P}$ mobilization by specific mechanisms.

In general, DGT and DET parameters are expressed in soil solution concentration (e.g., $\mathrm{mg} / \mathrm{L}$ ) while other P concentration in soils extracts are usually expressed per kg of soil dry weight. The lack of a constant solid to liquid ratio adds inaccuracies in back-calculating $\mathrm{P}_{\mathrm{DGT}}$ and $\mathrm{P}_{\mathrm{E}}$ concentrations on a dry weight basis. When compared to adsorbed concentrations, the solution concentrations (as used from DGT related data) are expected to be more realistic to those experienced by the plant, but harder to compare between soils due to their different wetting properties. Moisture is set to a maximum during slurry preparation, therefore the DGT method naturally accounts for differences soil wetting properties, which in turn are shown here to have significant impact on short-term P mobility. This may be one of the factors why $\mathrm{P}_{\mathrm{DGT}}$ have shown in some cases stronger correlation with plant $\mathrm{P}$ uptake compared with $\mathrm{P}_{\text {Olsen }}$ and other soil extracts. ${ }^{22,27}$

Drivers of Phosphorus Lability. Except for the sandy Tentsmuir soil, resupply from solid phase was considered small compared to other elements such as $\mathrm{Cd}, \mathrm{Cu}, \mathrm{Ni}$, and $\mathrm{Zn} .{ }^{10,18}$ For other elements, $T_{\mathrm{c}}$ usually ranged from 0.01 to $1000 \mathrm{~s}^{10}$ while here the majority of $T_{c}$ values were in the range of $1 \times 10^{4}$ to $1 \times 10^{5} \mathrm{~s}$ (20 samples, Table 4). Desorption rates are expected to be much slower than sorption rates and the $\mathrm{P}$ hysteretic behavior has been previously described by Okajima et al. (1983). ${ }^{28}$ The majority of desorption rate constants were in the range of $1 \times$ $10^{-6}$ to $1 \times 10^{-7}$ (18 samples, Table 4) averaging $1.29 \times 10^{-6} \mathrm{~s}^{-1}$. In previous studies the average $k_{-1}$ values were $2.9 \times 10^{-6} \mathrm{~s}^{-1}$ to 35 non calcareous soils ${ }^{29}$ and $1.4 \times 10^{-5} \mathrm{~s}^{-1}$ to 12 calcareous soils. ${ }^{30}$ Although different methodologies may affect the results of desorption studies, the average $k_{-1}$ values were similar between our data and previous research ${ }^{29,30}$ indicating that DGT and DIFS based estimation are in the expected range of variation.

Although $\mathrm{pH}$ is expected to be positively correlated to $\mathrm{P}$ desorption, ${ }^{29}$ for our soils $\mathrm{pH}$ was not correlated with $\mathrm{P}$ mobility parameters. No treatment was applied in our study to force $\mathrm{pH}$ shifts and observe its effect on $\mathrm{P}$ mobility parameters. The effect of natural $\mathrm{pH}$ values across different soils on $\mathrm{P}$ desorption, and the effect of $\mathrm{pH}$ changes within one specific soil (i.e., rhizosphere $\mathrm{pH}$ changes) are not necessarily the same. Similarly, particle size distribution was expected to significantly affect $\mathrm{P}$ desorption. ${ }^{31}$ Here, however, $\mathrm{P}$ resupply parameters were poorly correlated with particle size distribution. As our set of soil samples were very diverse in their intrinsic properties, the effects of $\mathrm{pH}$ and particle size distribution were probably overcome by other factors such as surface properties of clays and organic matter, and predominantly the fertilization history and the resulting $\mathrm{P}$ saturation of the soil exchange complex. Nevertheless, the use of median diameter (representative of particle size distribution) as a second response variable in multiple regression analysis was shown to significantly increase the explained variance for $\mathrm{P}_{\mathrm{DET}}, \mathrm{P}_{\mathrm{DGT}}$, and $\mathrm{P}_{\mathrm{E}}$ by $17 \%, 6.8 \%$, and $4.1 \%$ respectively (data not shown). This may indicate that particle size distribution is a secondary driver of $P$ mobility parameters.

The $P$ resupply from solid phase $\left(R-R_{\text {diff }}\right)$ and the desorption rates during DGT deployment were well correlated with $\mathrm{P}_{\mathrm{E}}$, $\mathrm{P}_{\mathrm{DGT}}$, and most of the $\mathrm{P}$ concentrations in different tests. This was considered hard evidence that $\mathrm{P}$ status is the main driver of $\mathrm{P}$ resupply from soil solid phase into solution, and hence $\mathrm{P}$ lability and bioavailability. In general, the soils with extreme $\mathrm{P}_{\text {Olsen }}$ were also extreme in P mobility and resupply parameters (Figures 1B, $\mathrm{D}, \mathrm{E}$, and F). Long-term $\mathrm{P}$ fertilization rates are directly proportional to the degree of soil saturation with $\mathrm{P}$ and the concomitant reduction P-retention capacity. ${ }^{32}$ Many European soils are excessively fertilized, accumulating soil $\mathrm{P}$ pools to environmentally unacceptable levels. ${ }^{33,34}$ This is certainly reflected in our soil sample set as $81.25 \%$ of the samples belong to P fertility indexes over three corresponding to "high" and "very high" $\mathrm{P}$ availability. The wide range of soil types and $P$ concentration of our sample set, gives strong support to the case that soil P status (and the assumed related saturation of the soil interchange complexes) is the main driver of $\mathrm{P}$ resupply from soil solid phase into solution, and hence $\mathrm{P}$ lability. More data from a bigger sample set including other soils types and conditions are required to further verify these conclusions.

Environmental Implications. The high P status in soils and the resulting nutrient pollution of receiving water courses are a major environmental concern. Considering both freshwaters and oceans, current planetary conditions exceed all limits for $\mathrm{P}$ discharges. ${ }^{35}$ There is an urgent need to reduce total $\mathrm{P}$ in soils into environmentally acceptable levels, while maintaining optimal crop growth conditions. ${ }^{33}$ The chemical exchange of $\mathrm{P}$ between soil solid and solution phase is expected to be the main mechanism influencing the bioavailability of $\mathrm{P}$ to crops. The present work has provided new insight and an alternative approach for studying the dynamics and mobility of $\mathrm{P}$ in soil. High levels of available P were found using the DGT method among soils that represented a wide range of $\mathrm{P}$ indices. This unexpected result indicates that extract-based methods for estimating $\mathrm{P}$ availability may vastly overestimate fertilizer requirements and the risk of on-farm nutrient use and loss. The DGT method described herein could therefore be used to improve estimates of crop P requirements while minimizing the use of mineral fertilizers and the subsequent risks associated with surface water nutrient enrichment and eutrophication.

\section{ASSOCIATED CONTENT}

\section{Supporting Information}

The Supporting Information is available free of charge on the ACS Publications website at DOI: 10.1021/acs.est.5b05395.

Additional information as noted in the text (PDF)

\section{AUTHOR INFORMATION}

\section{Corresponding Authors}

*(D.M.-B.) E-mail: d.blackburn@lancaster.ac.uk.

*(H.Z.) E-mail: h.zhang@lancaster.ac.uk.

\section{Author Contributions}

The manuscript was drafted by Daniel Menezes-Blackburn, who also performed the DGT, DET, and DIFS analysis under direct supervision of Hao Zhang and Philip M. Haygarth. Patricia Cooper, Renate Wendler, Marc Stutter, Charles Shand, David Lumsdon, Timothy S. George, and Martin Blackwell were 
involved on the sample collection and characterization of P-related parameters. Courtney D. Giles, Tegan Darch, Catherine Wearing, and Lawrie Brown were involved in various laboratory analyses. All authors were involved in the conceptual planning, discussions and corrections of the manuscript.

\section{Notes}

The authors declare no competing financial interest. retired

\section{ACKNOWLEDGMENTS}

This work was performed as part of the Organic Phosphorus Utilisation in Soils (OPUS) project, funded by Biotechnology and Biological Sciences Research Council (BBSRC, BBSRC BB/K018167/1) in the UK. We thank the Scottish Government Rural Environment Research and Analysis Directorate for funding aspects of this research. We gratefully acknowledge the assistance of C. Taylor, H. Taylor , and S. Richards in soil collection and analysis, and the assistance of S. McGrath and J. Hernandez in data analysis.

\section{ABBREVIATIONS AND SYMBOLS}

$\mathrm{P}_{\mathrm{i}}$ inorganic phosphorus

$\mathrm{P}_{\mathrm{o}}$ oganic phosphorus measured as the difference between total and inorganic $P$

DGT diffusive gradients in thin films using a ferrihydrite containing gel as a $\mathrm{P}$ binding layer

DET diffusive equilibration in thin films (same DGT setup without the binding layer)

DIFS 'DGT induced fluxes in soils and sediments' model

$\mathrm{P}_{\mathrm{DET}}\left(\mathrm{mg} \mathrm{l}^{-1}\right)$ pore water (dissolved) $\mathrm{P}$ concentration determined using DET

$\mathrm{P}_{\text {DGT }}\left(\mathrm{mg} \mathrm{l}^{-1}\right)$ DGT measured time averaged soil solution $\mathrm{P}$ concentration at the surface of DGT device

$\mathrm{P}_{\mathrm{E}}$ effective $\mathrm{P}$ concentration - DGT estimated soil solution $\mathrm{P}+$ labile $\mathrm{P}$ concentration from the solid phase

$\mathrm{P}_{\text {Olsen }}\left(\mathrm{mg} \mathrm{kg}^{-1}\right)$ phosphorus concentration (solid phase) measured using $\mathrm{NaHCO}_{3}$ extraction

$\mathrm{D}_{0}\left(\mathrm{~cm}^{2} \mathrm{~s}^{-1}\right)$ diffusion coefficient in diffusive layer of DGT device

$\mathrm{D}_{\mathrm{s}}\left(\mathrm{cm}^{2} \mathrm{~s}^{-1}\right)$ diffusion coefficient in soil

$k_{-1}\left(s^{-1}\right)$ desorption rate constant

$k_{1}\left(\mathrm{~s}^{-1}\right)$ sorption rate constant

$K_{\mathrm{d}}\left(\mathrm{cm}^{3} \mathrm{~g}^{-1}\right)$ equilibrium distribution coefficient between solid phase and soil solution

$\mathrm{P}_{\mathrm{c}}\left(\mathrm{g} \mathrm{cm}^{-3}\right)$ particle concentration-mass of particles in unit volume of soil solution

$R$ ratio of $\mathrm{P}_{\mathrm{DGT}}$ to $\mathrm{P}_{\mathrm{DET}}$

$R_{\text {diff }}$ ratio of $\mathrm{P}_{\mathrm{DGT}}$ to $\mathrm{P}_{\mathrm{E}}$ in the case where there is no $\mathrm{P}$ resupply from the solid phase, estimated using DIFS for diffusion only case

$T_{\mathrm{c}}(\mathrm{s})$ response time of $(\mathrm{de})$ sorption process

$X_{\text {sol }}(\mathrm{cm})$ estimated distance to which DGT device depletes at least $5 \%$ of pore water $P$ concentrations

$X_{\text {ads }}(\mathrm{cm})$ estimated distance to which DGT device depletes at least $5 \%$ of adsorbed $P$ concentrations

WHC water holding capacity of the soil

MR maximum water retention in the soil prepared for DGT deployment

$\rho_{\mathrm{s}}$ bulk density of the soil at MR

$\rho_{\text {o }}$ bulk density of the dry soil

$\phi$ soil porosity

$\theta^{2}$ diffusive tortuosity

\section{REFERENCES}

(1) Batten, G. D. A review of phosphorus efficiency in wheat. Plant Soil 1992, 146 (1-2), 163-168.

(2) Vance, C. P.; Uhdeâ-Stone, C.; Allan, D. L. Phosphorus acquisition and use: critical adaptations by plants for securing a nonrenewable resource. New Phytol. 2003, 157 (3), 423-447.

(3) Syers, J.; Johnston, A.; Curtin, D. Efficiency of soil and fertilizer phosphorus use. Reconciling changing concepts of soil phosphorus behaviour with agronomic information. FAO Fertilizer and Plant Nutrition Bulletin 18. Exp. Agric. 2009, 45, 128.

(4) Li, L.; Stanforth, R. Distinguishing adsorption and surface precipitation of phosphate on goethite $(\mathrm{FeOOH})$. J. Colloid Interface Sci. 2000, 230 (1), 12-21.

(5) Nye, P. The rate-limiting step in plant nutrient absorption from soil. Soil Sci. 1977, 123 (5), 292-297.

(6) Degryse, F.; Smolders, E.; Zhang, H.; Davison, W. Predicting availability of mineral elements to plants with the DGT technique: a review of experimental data and interpretation by modelling. Environ. Chem. 2009, 6 (3), 198-218.

(7) Harper, M. P.; Davison, W.; Zhang, H.; Tych, W. Kinetics of metal exchange between solids and solutions in sediments and soils interpreted from DGT measured fluxes. Geochim. Cosmochim. Acta 1998, 62 (16), 2757-2770.

(8) Harper, M. P.; Davison, W.; Tych, W. DIFS - a modelling and simulation tool for DGT induced trace metal remobilisation in sediments and soils. Environ. Modell. Softw. 2000, 15 (1), 55-66.

(9) Zhang, H.; Zhao, F.-J.; Sun, B.; Davison, W.; Mcgrath, S. P. A new method to measure effective soil solution concentration predicts copper availability to plants. Environ. Sci. Technol. 2001, 35 (12), 2602-2607.

(10) Zhang, H.; Lombi, E.; Smolders, E.; McGrath, S. Kinetics of Zn release in soils and prediction of $\mathrm{Zn}$ concentration in plants using diffusive gradients in thin films. Environ. Sci. Technol. 2004, 38 (13), $3608-3613$.

(11) Stutter, M. I.; Shand, C. A.; George, T. S.; Blackwell, M. S. A.; Dixon, L.; Bol, R.; MacKay, R. L.; Richardson, A. E.; Condron, L. M.; Haygarth, P. M. Land use and soil factors affecting accumulation of phosphorus species in temperate soils. Geoderma 2015, 257-258, 257258.

(12) Zhang, H.; Davison, W. Performance characteristics of diffusion gradients in thin films for the in situ measurement of trace metals in aqueous solution. Anal. Chem. 1995, 67 (19), 3391-3400.

(13) Santner, J.; Prohaska, T.; Luo, J.; Zhang, H. Ferrihydrite containing gel for chemical imaging of labile phosphate species in sediments and soils using diffusive gradients in thin films. Anal. Chem. 2010, 82 (18), 7668-7674.

(14) Murphy, J.; Riley, J. A modified single solution method for the determination of phosphate in natural waters. Anal. Chim. Acta 1962, 27, $31-36$.

(15) Zhang, H.; Davison, W.; Knight, B.; McGrath, S. In situ measurements of solution concentrations and fluxes of trace metals in soils using DGT. Environ. Sci. Technol. 1998, 32 (5), 704-710.

(16) DEFRA, D. f. E. Food and Rural Affairs, Fertiliser manual (RB209), 8th ed; The Stationery Office: London, 2010.

(17) Wang, X.; Yost, R.; Linquist, B. Soil aggregate size affects phosphorus desorption from highly weathered soils and plant growth. Soil Sci. Soc. Am. J. 2001, 65 (1), 139-146.

(18) Ernstberger, H.; Davison, W.; Zhang, H.; Tye, A.; Young, S. Measurement and dynamic modeling of trace metal mobilization in soils using DGT and DIFS. Environ. Sci. Technol. 2002, 36 (3), 349-354.

(19) Ernstberger, H.; Zhang, H.; Tye, A.; Young, S.; Davison, W. Desorption kinetics of $\mathrm{Cd}, \mathrm{Zn}$, and Ni measured in soils by DGT. Environ. Sci. Technol. 2005, 39 (6), 1591-1597.

(20) Mallarino, A.; Blackmer, A. Comparison of methods for determining critical concentrations of soil test phosphorus for corn. Agron. J. 1992, 84 (5), 850-856.

(21) van Raij, B. Bioavailable tests: alternatives to standard soil extractions. Commun. Soil Sci. Plant Anal. 1998, 29 (11-14), 15531570. 
(22) Six, L.; Smolders, E.; Merckx, R. The performance of DGT versus conventional soil phosphorus tests in tropical soils - maize and rice responses to P application. Plant Soil 2013, 366 (1-2), 49-66.

(23) Ciffroy, P.; Nia, Y.; Garnier, J. Probabilistic multicompartmental model for interpreting DGT kinetics in sediments. Environ. Sci. Technol. 2011, 45 (22), 9558-9565.

(24) Lehto, N.; Sochaczewski, Å.; Davison, W.; Tych, W.; Zhang, H. Quantitative assessment of soil parameter (KD and TC) estimation using DGT measurements and the 2D DIFS model. Chemosphere 2008, 71 (4), 795-801.

(25) Richardson, A. E.; Hocking, P. J.; Simpson, R. J.; George, T. S. Plant mechanisms to optimize access to soil phosphorus. Crop Pasture Sci. 2009, 60, 124-143.

(26) Hinsinger, P. Bioavailability of soil inorganic $P$ in the rhizosphere as affected by root-induced chemical changes: a review. Plant Soil 2001, 237 (2), 173-195.

(27) Tandy, S.; Mundus, S.; Yngvesson, J.; de Bang, T. C.; Lombi, E.; Schjoerring, J. K.; Husted, S. r. The use of DGT for prediction of plant available copper, zinc and phosphorus in agricultural soils. Plant Soil 2011, 346 (1-2), 167-180.

(28) Okajima, H.; Kubota, H.; Sakuma, T. Hysteresis in the phosphorus sorption and desorption processes of soils. Soil Sci. Plant Nutr. 1983, 29 (3), 271-283.

(29) Smet, J. D.; Vanderdeelen, J.; Hofman, G. Effect of soil properties on the kinetics of phosphate release. Commun. Soil Sci. Plant Anal. 1998, 29 (11-14), 2135-2147.

(30) Shariatmadari, H.; Shirvani, M.; Jafari, A. Phosphorus release kinetics and availability in calcareous soils of selected arid and semiarid toposequences. Geoderma 2006, 132 (3), 261-272.

(31) Barros, N. F.; Comerford, N. B. Phosphorus sorption, desorption and resorption by soils of the Brazilian Cerrado supporting eucalypt. Biomass Bioenergy 2005, 28 (2), 229-236.

(32) Hooda, P.; Truesdale, V.; Edwards, A.; Withers, P.; Aitken, M.; Miller, A.; Rendell, A. Manuring and fertilization effects on phosphorus accumulation in soils and potential environmental implications. Adv. Environ. Res. 2001, 5 (1), 13-21.

(33) Barberis, E.; Marsan, F. A.; Scalenghe, R.; Lammers, A.; Schwertmann, U.; Edwards, A.; Maguire, R.; Wilson, M.; Delgado, A.; Torrent, J. European soils overfertilized with phosphorus: Part 1. Basic properties. Fert. Res. 1995, 45 (3), 199-207.

(34) Liu, Y.; Pan, X.; Li, J. A 1961-2010 record of fertilizer use, pesticide application and cereal yields: a review. Agron. Sustainable Dev. 2015, 35 (1), 83-93.

(35) Carpenter, S. R.; Bennett, E. M. Reconsideration of the planetary boundary for phosphorus. Environ. Res. Lett. 2011, 6 (1), 014009. 